\title{
Colour, Morphological and Surface Textural Characteristics of the Diamonds in Venetia Kimberlites
}

\author{
Robinson, D.N. ${ }^{1}$, Ferraris, R. ${ }^{2}$, Anderson, V.G. ${ }^{2}$, Parker, G.M. ${ }^{2}$, Van Blerck, E. ${ }^{2}$ and Hart, D. ${ }^{2}$ \\ 1. Anglo American Research Laboratories, P.O. Box 106, Crown Mines, 2025, South Africa. \\ 2. CSO Valuations (Pty.) Ltd., P.O. Box 633, Kimberley, 8300, South Africa
}

\section{Introduction}

The Venetia kimberlite cluster consists of nine pipe and pipe-like bodies and two sets of dykes. A mine on the largest pipe was opened in 1992. The two largest pipes in the cluster, K1 and K2, are currently being exploited and annual production exceeds four million carats at an average recovery grade of close to $130 \mathrm{cpht}$.

Geological investigations produced diamond samples of a few to a few hundred carats from specific kimberlite bodies and discrete intrusions within some bodies. The larger of these samples have been studied in terms of the colour, morphological and surface textural features of individual diamonds and generalised observations are reported here. The largest sample, of 550 carats, represents tuffisitic kimberlite breccia (TKB) in K1. Hypabyssal kimberlite in the east of $\mathrm{K} 1$, and the $\mathrm{K} 2$ pipe (consisting of TKB and hypabyssal kimberlite in similar proportions), and also represented by fairly substantial samples while much smaller samples (approximately 10 carats each) were examined from the K3, K4 Central (both mostly transitional between TKB and hypabyssal kimberlite) and K6 bodies. The ensuing discussion therefore concentrates on the K1 (TKB), K1 (Hypabyssal) and K2 (mixed TKB/hypabyssal) samples.

Most of the diamond features considered here are illustrated in Robinson et al. (1989).

\section{Observations}

Observations of interest are summarised, for diamonds in the minus 6 plus 5 (diamond sieve) size class (i.e. mostly between 0,05 and 0,08 carat in size), in the accompanying table.

The proportion of brown diamonds varies considerably between samples. Thus, only 15 per cent of the K2 diamonds are brown, the proportion is nearly three times as great in the K1 Hypabyssal sample and the small K4 Central and K6 samples consist mainly of brown stones. While green staining is very common in some of the samples, this probably only accounts for a small part of the differences noted for brown stones. This is because the staining is generally too light to mask anything but the lightest brown colour while the incidence of brown colour correlates, anyway, with that of lamination lines (ascribed to plastic deformation which is considered responsible for much of the brown colour in diamond).

The "rounded dodecahedral" crystal form dominates in all of the samples. The octahedron is also common, to a similar degree, in most of the samples, while the cube is rare (excepting as a subordinate form).

Some 25 to 30 per cent of crystals are macles in most of the samples except K2 in which they, and aggregates, are relatively scarce. 
Pseudohemimorphism is a particularly common crystal peculiarity of most of the samples. The resulting "ice-cream cone" crystals (in which an octahedral portion resembles the biscuit cone and a "rounded dodecahedral" portion resembles the scoop of ice-cream) are considered to represent original octahedra that protruded from protective xenoliths during the resorption responsible for developing the "rounded dodecahedral" form.

Both the discrete and finely spaced varieties of lamination lines are common dodecahedral surface features, particularly on the brown diamonds in the samples. Corrosion sculpturing is particularly common only in one of the small samples (K4 Central).

\section{The Percentages (except for $\mathrm{N}$ ) of Diamonds Exhibiting Particular Features}

\begin{tabular}{||l|c|c|c||c|c|c||}
\hline & $\begin{array}{c}\text { K1 } \\
\text { TKB }\end{array}$ & $\begin{array}{c}\text { K1 } \\
\text { Hyp }\end{array}$ & $\begin{array}{c}\text { K2 } \\
\text { T + H }\end{array}$ & $\begin{array}{c}\text { K3 } \\
\text { Trans }\end{array}$ & $\begin{array}{c}\text { K4C } \\
\text { Trans }\end{array}$ & K6 \\
\hline \hline $\mathbf{N}$ & 356 & 90 & 165 & 16 & 20 & 16 \\
\hline $\begin{array}{l}\text { Colour: } \\
\text { Green Stained }\end{array}$ & 34 & 26 & 55 & 25 & 5 & 13 \\
\hline Brown & 30 & 44 & 15 & 25 & 95 & 88 \\
\hline $\begin{array}{l}\text { Main Form: } \\
\text { Octahedron }\end{array}$ & 30 & 32 & 26 & 13 & 25 & 25 \\
\hline "Rounded Dodec." & 70 & 68 & 73 & 75 & 75 & 75 \\
\hline Cube & Tr & 0 & 1 & 0 & 0 & 0 \\
\hline $\begin{array}{l}\text { Subordinate Form: } \\
\text { Octahedron }\end{array}$ & 17 & 27 & 14 & 19 & 15 & 19 \\
\hline Cube & 19 & 28 & 32 & 31 & 35 & 6 \\
\hline (Breakage) & 26 & 39 & 13 & 25 & 20 & 13 \\
\hline $\begin{array}{l}\text { Twinning: } \\
\text { Macle }\end{array}$ & 26 & 31 & 10 & 25 & 15 & 31 \\
\hline Aggregate & 3 & 6 & 1 & 13 & 10 & 13 \\
\hline $\begin{array}{l}\text { Crystal Peculiarities: } \\
\text { Pseudohemimorphism }\end{array}$ & 18 & 10 & 13 & 6 & 0 & 19 \\
\hline $\begin{array}{l}\text { Dodec. Surface Textures: } \\
\text { Terracing }\end{array}$ & 10 & 22 & 18 & 19 & 5 & 0 \\
\hline Discrete Lamination Lines & 19 & 11 & 10 & 13 & 15 & 25 \\
\hline Fine Lamination Lines & 38 & 39 & 17 & 19 & 85 & 38 \\
\hline Microdisk Pattern & 4 & 3 & 1 & 0 & 0 & 0 \\
\hline Corrosion Sculpture & 13 & 2 & 5 & 0 & 35 & 6 \\
\hline \hline
\end{tabular}

\section{Discussion}

The dominance of the octahedral diamond growth form over the cube in all of the samples is compatible with all of the diamond populations coming from the same mantle source region. This might not apply entirely in the K2 case, however, in view of its relatively low contents of macles and aggregates. Considering that the plastic deformation of diamonds probably occurs in the upper mantle conduits of kimberlite magmas (cf. Robinson et al., 1989), separate emplacement events, from the upper mantle, are suggested for the kimberlites hosting each diamond sample. Alternatively, the same variations in the proportions of brown colour and plastic deformation features could be achieved by a single surge of kimberlite magma in which, however, the proportion of deformed mantle material fluctuates. The similar, octahedron/"rounded dodecahedron" 
relationships (indicating similar degrees of resorption) and similar and unusually high incidences of pseudohemimorphic crystals in most of the samples, both suggest uniformity during kimberlite magma emplacement, thereby favouring the second alternative.

The incidence of corrosion sculpturing seems not to reflect diatreme root zone conditions as well as observed previously by Robinson et al. (op. cit.).

\section{Reference}

Robinson, D.N., Scott, J.A., Van Niekerk, A., and Anderson, V.G., 1989, The sequence of events reflected in the diamonds of some southern African kimberlites. In: Kimberlites and Related Rocks, Vol. 2, Their Mantle/Crust Setting, Diamonds and Diamond Exploration. Soc. of Australia Spec. Pub. No. 14, p. 990-1000. 